\title{
Effect of docetaxel-loaded lipid microbubble in combination with ultrasound-triggered microbubble destruction on the growth of a gastric cancer cell line
}

\author{
BIN LAI $^{1}$, PEIQIAN ZHU ${ }^{1 *}$, HONGLANG LI ${ }^{1 *}$, LIN HU $^{1 *}$ and JIWEI WANG ${ }^{2}$ \\ Departments of ${ }^{1}$ General Surgery and ${ }^{2}$ Ultrasonography, The Second Affiliated Hospital of Nanchang University, \\ Nanchang, Jiangxi 330006, P.R. China
}

Received March 18, 2018; Accepted April 3, 2019

DOI: $10.3892 / \mathrm{ol} .2019 .10289$

\begin{abstract}
Although gastric cancer therapy has been improved, more efficient treatment strategies still need to be developed. In the present study, a docetaxel (DOC)-loaded lipid microbubble (DLLD) was prepared and the effect of DLLD combined with ultrasound-triggered microbubble destruction (UTMD) on the growth of a gastric cancer cell line was investigated. The following four groups were included in the present study: Control, DOC, DLLD and DLLD plus UTMD. The determined entrapment efficiency of DLLD is $76 \pm 3.5 \%$. The present study demonstrated that treatment with DLLD plus UTMD could significantly inhibit the growth of the cultured gastric cancer cell line BGC-823 via arresting the cell cycle in $\mathrm{G}_{2} / \mathrm{M}$ phase, inhibiting cell DNA synthesis, promoting cell apoptosis and disrupting mitochondrial membrane potential, as compared with treatment with DOC or DLLD alone. Furthermore, the expression of p53, p21 and Bax were identified to be significantly upregulated, while that of Bcl-2 was significantly downregulated in the DLLD plus UTMD group. Therefore, treatment with DLLD plus UTMD was more efficient in inhibiting cell proliferation and inducing cell apoptosis in the gastric cancer cell line, when compared with treatment with DOC or DLLD alone, suggesting that DLLD plus UTMD could serve as a promising strategy for the treatment of gastric cancer.
\end{abstract}

Correspondence to: Dr Jiwei Wang, Department of Ultrasonography, The Second Affiliated Hospital of Nanchang University, 1 Minde Road, Nanchang, Jiangxi 330006, P.R. China E-mail: wangjiweii67@163.com

*Contributed equally

Key words: docetaxel-loaded lipid microbubble, ultrasoundtriggered microbubble destruction, targeted gastric cancer therapy, cell proliferation, cell apoptosis

\section{Introduction}

Gastric cancer is one of the most common epithelial malignant types of cancer, and is a serious threat to human health (1). Due to specific eating habits, climate and geographical position, China is one of the countries with the highest incidence of gastric cancer (2). Numerous factors have been reported to contribute to the occurrence of gastric cancer, including helicobacter pylori infection (3), lifestyle (4), socioeconomic status (5), environmental (6) and genetic factors (7-9). For gastric cancer in the early stages of disease, surgical resection is the primary therapeutic strategy, whereas the conventional treatment for advanced gastric cancer is surgical resection combined with chemotherapy $(10,11)$. However, chemotherapy drugs do not only destroy tumor cells, but also attack normal cells, which can result in severe side effects for the patient (12). Therefore, efforts should be made to develop safe tumor-targeting therapeutic strategies.

Previous studies have focused on using ultrasound-triggered microbubble destruction (UTMD) for the treatment of cancer $(13,14)$. Lipid microbubbles, which are widely used as acoustic contrast agents, are also considered to function as good carriers for drug delivery (15-17). The diameter of a nanoscale lipid microbubble is shorter than that of a red blood cell, therefore, it can freely flow with the blood into the pulmonary circulation without blocking it (18). In addition, a nanoscale lipid microbubble can pass through the vascular endothelial cell gap to reach the tissues outside the vessels (18). Drugs loaded lipid microbubbles (DLLMs) can be monitored dynamically by ultrasound (19). Once the microbubbles gather in a tumor-containing organ, relatively low-dose ultrasound was used to irradiate the target organ to destroy the microbubble and release the drugs (19). Following ultrasound irradiation, the loaded drug was rapidly released to the target region to form a relatively high drug concentration $(19,20)$. Furthermore, ultrasound-induced mechanical stress resulting in an enlarged cell gap and increased permeability of the cell membrane has been shown to further increase the intracellular diffusion of the drug (21-24). Therefore, UTMD combined with DLLD may serve as an effective tumor-targeting strategy.

Docetaxel (DOC), a well-known anti-cancer drug, has been demonstrated to be effective for the treatment of 
advanced gastric cancer (25-27). In the present study, lipid microbubbles containing DOC were prepared, and the effects of DOC-loaded microbubbles combined with UTMD on the growth of a gastric cell line were investigated.

\section{Materials and methods}

Preparation of DLLD. The DOC-loaded lipid microbubble (DLLD) was prepared as previously described (28). Briefly, 1,2-Dipalmitoyl-sn-glycero-3-phosphocholine, Distearoylphosphatidylcholine, Dipalmitoyl phosphatidylethanolamine (all from Sigma-Aldrich, Darmstadt, Germany) and DOC (MedChemExpress, Monmouth Junction, NJ, USA) were mixed to a mass ratio of 1:5:2:2. The mixture was dissolved in chloroform and methanol (1:1, v:v) solution. Following rotary vacuum evaporation, glycerol/PBS (1:9, v:v) was added to form DOC/lipid solution $(20 \mathrm{mg} / \mathrm{ml})$. Following perfusion with perfluoropropane gas and mechanical vibration, DLLD was obtained. The unembedded DOC was removed by washing in PBS for $15 \mathrm{~min}$ at $4^{\circ} \mathrm{C}$. The entrapment efficiency of DLLD was determined by Reverse-Phase High Performance Liquid Chromatography (RP-HPLC; Dalian Elite Analytical Instruments Co., Ltd,). The reverse-phase SinoChrom ODS-BP column ( 200 x $4.6 \mathrm{~mm}$ i.d., pore size $5 \mu \mathrm{m}$; Dalian Elite Analytical Instruments Co., Ltd.,) was used at a temperature of $30^{\circ} \mathrm{C}$. The mobile phase was composed of methanol/acetonitrile/water (50:30:20; v/v) at a flow rate of $1 \mathrm{ml} / \mathrm{min}$. UV absorbance detection was set at $230 \mathrm{~nm}$. The sample quantity was $20 \mu \mathrm{l}$. A series of dilutions of $\operatorname{DOC}(0.1,0.5,2.5,10$, 25,50 and $100 \mu \mathrm{g} / \mathrm{ml}$ ) were made to detect the area under the curve, and a linear calibration curve correlating the area under the curve and concentration of DOC was constructed. The concentration of free DOC was calculated according to the linear calibration curve.

Cell culture and treatment. The gastric cancer cell line BGC-823 was purchased from the Shanghai Institute of Cell Biology (Shanghai, China) and maintained in DMEM medium (Thermo Fisher Scientific, Inc., Waltham, MA, USA) containing 10\% FBS (Thermo Fisher Scientific, Inc.) supplemented with $100 \mathrm{U} / \mathrm{ml}$ penicillin and $100 \mu \mathrm{g} / \mathrm{ml}$ streptomycin. In the present study, BGC-823 cells were divided into 4 groups: Control, DOC, DLLD and DLLD + UTMD. In the control group, BGC-823 cells were treated with PBS. In the DOC group, BGC-823 cells were treated with $4 \mu \mathrm{M}$ DOC. In the DLLD group, DLLD (21.3 mg/l) which was equal to $4 \mu \mathrm{M}$ DOC was used. In the DLLD plus UTMD group, DLLD-treated cells received ultrasound irradiation $\left(0.5 \mathrm{~W} / \mathrm{cm}^{2}, 1 \mathrm{MHz}\right)$ for $30 \mathrm{sec}$. Cells were treated with PBS, DOC or DLLD for $48 \mathrm{~h}$ at $37^{\circ} \mathrm{C}$.

Cell viability assay. BGC-823 cells were seeded on a 96-well plate at a density of $3 \times 10^{3}$ per well and cultured for 24, 48 and 72 h, respectively. A Cell Counting Kit 8 (CCK8; MedChemExpress) was used for cell viability detection. Briefly, cells were incubated with CCK8 (10 $\mu \mathrm{l} /$ well) for $3 \mathrm{~h}$ at $37^{\circ} \mathrm{C}$. Optical density (OD) was read at $450 \mathrm{~nm}$ using a microplate reader. Cell inhibition was calculated according to the formula $1-\mathrm{OD}^{\text {expremental group }} / \mathrm{OD}^{\text {control group }}$.
BrdU incorporation assay. A BrdU cell proliferation ELISA kit (Abcam, Cambridge, MA, USA) was used to quantify cells in DNA synthesis. Briefly, cells were incubated with fresh medium containing BrdU solution for $12 \mathrm{~h}$ at $37^{\circ} \mathrm{C}$. After removing the medium and being washed in PBS for $5 \mathrm{~min}$ at room temperature (RT), cells were fixed in $4 \%$ paraformaldehyde solution for $10 \mathrm{~min}$ at RT and incubated with primary BrdU antibody for $1 \mathrm{~h}$ at RT. Cells were subsequently incubated with the secondary antibody for $30 \mathrm{~min}$ at RT. Following incubation of cells with TMD and stop solution, the absorbance was determined at $450 \mathrm{~nm}$ using a microplate reader (Thermo Fisher Scientific, Inc., USA).

Flow cytometric analysis. Cells in the different experimental groups were digested using $0.25 \%$ trypsin and homogenized by pipetting. For cell cycle analysis, cells were centrifuged at $1,000 \times \mathrm{g}$ for $5 \mathrm{~min}$ at RT and re-suspended in $70 \%$ cold ethanol and stored at $4{ }^{\circ} \mathrm{C}$ overnight. The ethanol was removed by centrifugation $(1,000 \mathrm{x}$ g for $5 \mathrm{~min}$ at $\mathrm{RT})$ and cells were washed in PBS for $5 \mathrm{~min}$ at RT. Cells were then incubated with propidium iodide (PI; Thermo Fisher Scientific, Inc, USA) for $30 \mathrm{~min}$ at $4^{\circ} \mathrm{C}$ in the dark. Immediately following this incubation, the samples were detected using a flow cytometer (Becton-Dickinson, Heidelberg, Germany). The data were analyzed by FlowJo 7.6 software (Stanford University, California, USA).

For cell apoptosis detection, an Annexin V-FITC Apoptosis Detection kit (Vazyme Biotech, Co., Ltd., Nanjing, China) was used. Following staining with Annexin V and PI for 15 min in the dark, samples were immediately detected using a flow cytometer (Becton, Dickinson and Company). The data were analyzed using FlowJo 7.6.1 software (FlowJo LLC).

For mitochondrial membrane potential (MMP) detection, a JC-1 MMP detection kit (Beyotime Institute of Biotechnology, Haimen, China) was used. Cells treated with carbonyl cyanide 3 -chlorophenylhydrazone were set as the positive control. Cells were incubated with $\mathrm{JC}-1(5 \mathrm{mg} / \mathrm{l})$ for $1 \mathrm{~h}$ at $37^{\circ} \mathrm{C}$. The unbound JC-1 was removed by washing in PBS. Samples were immediately detected using a flow cytometer (Becton, Dickinson and Company). The data were analyzed by Flow Jo 7.6 software (Stanford University, California, USA). When the MMP is high, JC-1 aggregates to form a polymeric compound (red fluorescence) in the matrix of mitochondria. On the contrary, JC-1 cannot aggregate and exists as a JC-1 monomer (green fluorescence) (29). Therefore, the MMP was calculated as the ratio of red fluorescence intensity to green fluorescence intensity.

Western blot analysis. BGC-823 cells were harvested and lysed in RIPA solution (Beyotime Institute of Biotechnology) containing phenylmethanesulfonyl fluoride (PMSF) and phosphatase inhibitor. Following centrifugation $(13,000 \mathrm{x} \mathrm{g}$ for $15 \mathrm{~min}$ at $4^{\circ} \mathrm{C}$ ), the supernatant was collected. The protein content for each sample was determined using the bicinchoninic acid assay method. The protein $(25 \mu \mathrm{g} / \mathrm{lane})$ was separated by sodium dodecyl sulfate polyacrylamide gel electrophoresis using a $10 \%$ gel. The fractioned proteins in the gel were transferred onto a PVDF membrane. Following immersion in 5\% milk/PBST for $1 \mathrm{~h}$ at RT, the membrane was incubated with the primary antibodies, including p53 (dilution 
A

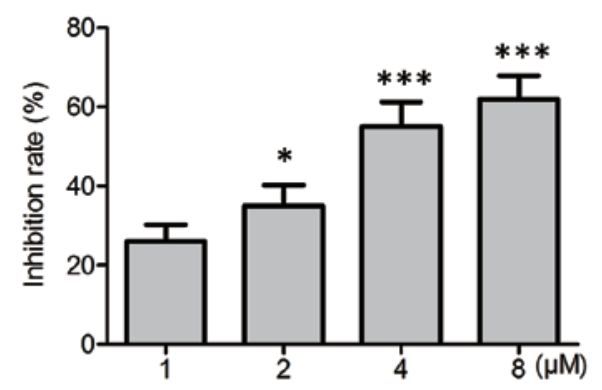

B

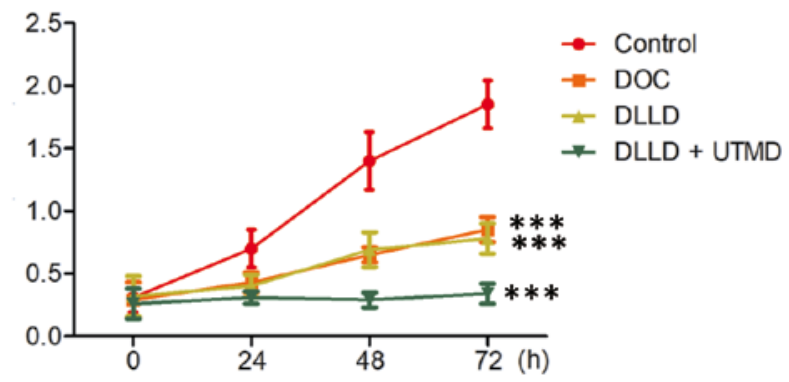

Figure 1. Effect of DLLD combined with UTMD on BGC-823 cell growth. (A) Cells were incubated with indicated doses of DOC for 48 h and cell viability was determined by the CCK- 8 assay. The inhibition rate was calculated. ${ }^{*} \mathrm{P}<0.05$ and ${ }^{* * *} \mathrm{P}<0.001$ vs. $1 \mu \mathrm{M}$. (B) Cells were treated with PBS, DOC, DLLD or DLLD plus UTMD for the indicated times, and cell viability was determined by the CCK- 8 assay. Values are presented as the mean \pm SD. $n=5$ for each group. ${ }^{* * * *} \mathrm{P}<0.001$ vs. Control. DOC, docetaxel; DLLD, DOC-loaded lipid microbubble; UTMD, ultrasound-triggered microbubble destruction; OD, optical density; CCK-8, Cell Counting Kit-8.

1:500; cat. no. ab26), p21 (dilution 1:1,000; cat. no. ab109520), Bcl-2 (dilution 1:1,000; cat. no. ab32124) and Bax (dilution 1:1,000; cat. no. ab32503; all Abcam) at $4^{\circ} \mathrm{C}$ overnight. The unbound primary antibodies in the membranes were removed by washing in PBS for $15 \mathrm{~min}$ at RT. The membranes were then incubated with the corresponding HRP-conjugated goat anti-rabbit (dilution 1:3,000; cat. no. ab6721) and goat anti mouse (dilution 1:3,000; cat. no. ab205719; all from Abcam) secondary antibodies at room temperature for $1 \mathrm{~h}$. Protein bands in the membrane were visualized following staining with enhanced chemiluminescence solution.

Statistical analysis. Data are expressed as the mean \pm SD. One-way ANOVA was used for statistics among groups. When ANOVA was significant, it was followed by a post-hoc Fishers least significant difference test. $\mathrm{P}<0.05$ was considered to indicate a statistically significant difference. The SPSS 19.0 software package was used to perform statistical analyses (IBM Corp.).

\section{Results}

Effect of DLLD combined with UTMD on BGC-823 cell growth. To identify an optimal inhibitory dose of DOC on the growth of BGC- 823 cells, BGC- 823 cells were treated with serial concentrations of DOC $(1,2,4$ and $8 \mu \mathrm{M})$ for $48 \mathrm{~h}$. The results demonstrated that DOC significantly inhibited the growth of BGC-823 in a dose-dependent manner, and the optimum inhibition was observed at a dose of $4 \mu \mathrm{M}$ (Fig. 1A). As a result, $4 \mu \mathrm{M}$ DOC was subsequently used in the present study.

Cells were treated with vehicle, DOC, DLLD (capsulation efficiency, 76 $\pm 3.5 \%$ ) and DLLD plus UTMD for $0,24,48$ and $72 \mathrm{~h}$ respectively. The results demonstrated that treatment with DLLD plus UTMD significantly inhibited the growth of BGC-823 cells compared with DOC or DLLD treatment alone (Fig. 1B). The inhibitory effect of DOC and DLLD alone were similar (Fig. 1B).

Effect of DLLD combined with UTMD on BGC-823 cell cycle. Cell cycle analysis revealed that DOC, DLLD and DLLD plus UTMD could significantly decrease the proportion of cells in the $S$ phase and increase it in the $G_{2} / M$ phase when compared with the control (Fig. 2A). However, treatment with DLLD plus UTMD could further decrease the proportion of cells in the $S$ phase and increase it in the $G_{2} / M$ phase when compared with treatment with DOC or DLLD alone (Fig. 2A). No significant differences were observed between the DOC and DLLD groups (Fig. 2A). This result was further confirmed by analysis of BrdU incorporation and the expression of cell cycle-regulating proteins. Among the four groups, BrdU incorporative cells were the lowest and the expression of p53 and p21 the highest in the DLLD plus UTMD group (Fig. 2B-E).

Effect of DLLD combined with UTMD on BGC-823 cell apoptosis. The cell apoptosis assay revealed that DOC, DLLD and DLLD plus UTMD could significantly induce apoptosis in BGC-823 cells when compared with the control (Fig. 3A and B). However, treatment with DLLD plus UTMD could further promote cell apoptosis when compared with treatment with DOC or DLLD alone (Fig. 3A and B). The levels of cell apoptosis in the DOC and DLLD treatment groups were similar (Fig. 3A and B).

Effect of DLLD combined with UTMD on the MMP of $B G C-823$ cells. The results of MMP analysis revealed that treatment with DLLD plus UTMD significantly decreased the MMP level of BGC-823 cells when compared with treatment with DOC or DLLD alone (Fig. 4A). It was also demonstrated that the expression of $\mathrm{Bcl}-2$ was lowest and the expression of Bax highest in the DLLD plus UTMD group (Fig. 4B-D).

\section{Discussion}

DOC can bind and stabilize intracellular microbubbles, thus disrupting the dynamic balance of microtubule assembly and disassembly, resulting in cell death (30). Due to this property, DOC has been widely used for the treatment of several types of cancer, including gastric cancer (31). However, as a cell cycle inhibitor, DOC is toxic to normal cells, which can result in numerous side effects, including hair loss, neutropenia and anemia (32). Therefore, more tumor-targeting strategies need to be developed. Due to its ability to deliver drugs to the target area, while 
A

A

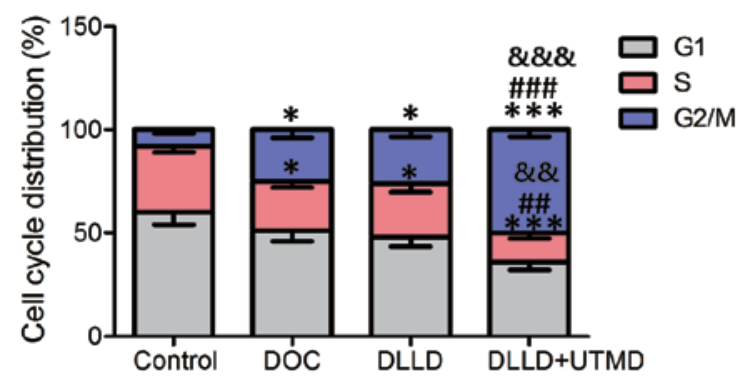

C

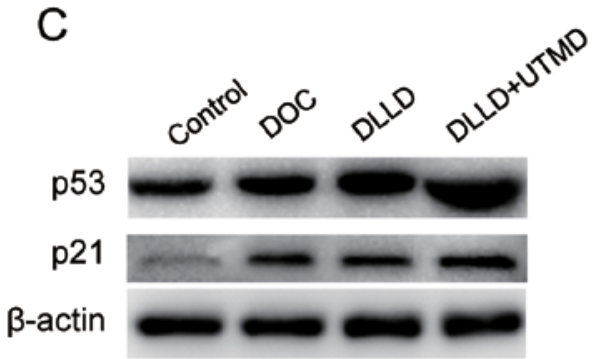

B

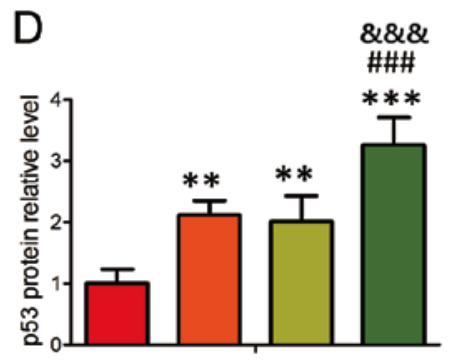

$\square$ Control

$\square \mathrm{DOC}$

$\square$ DLLD

$\square$ DLLD + UTMD

Figure 2. Effect of DLLD combined with UTMD on the BGC-823 cell cycle. Cells were treated with PBS, DOC, DLLD or DLLD plus UTMD for 48 h. (A) Cell cycle analysis by propidium iodide staining. (B) Brdu incorporation assay. (C) Western blot analysis of p53 and p21 expression. Quantified protein levels of (D) $p 53$ and (E) p21. Values are presented as the mean $\pm \mathrm{SD}$ ( $\mathrm{n}=5$ for each group). ${ }^{*} \mathrm{P}<0.05,{ }^{* * *} \mathrm{P}<0.01$ and ${ }^{* * * *} \mathrm{P}<0.001$ vs. Control. ${ }^{\# \#} \mathrm{P}<0.01$ and ${ }^{\# \# \#} \mathrm{P}<0.001$ vs. DOC. ${ }^{\& \&} \mathrm{P}<0.01$ and ${ }^{\& \& \&} \mathrm{P}<0.001$ vs. DLLD. DOC, docetaxel; DLLD, DOC-loaded lipid microbubble; UTMD, ultrasound-triggered microbubble destruction.

A

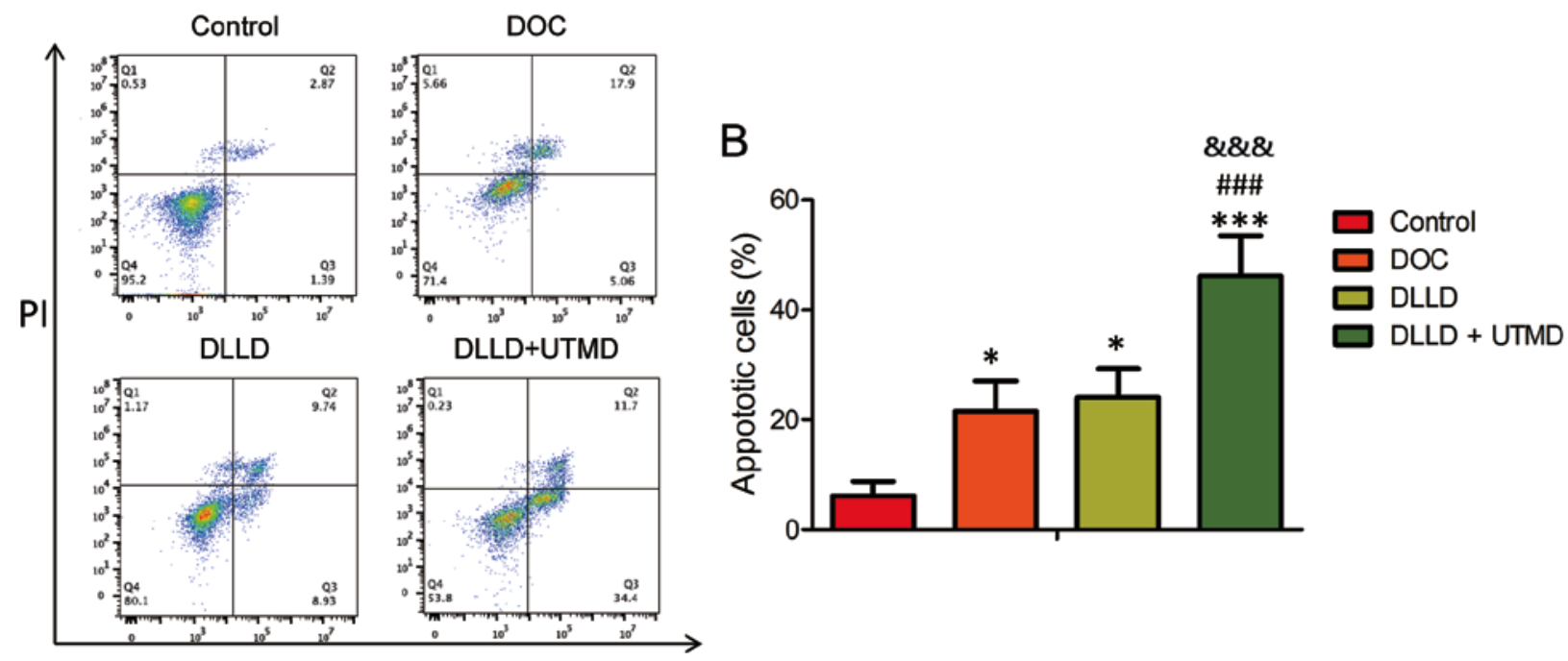

\section{Annexin V}

Figure 3. Effect of DLLD combined with UTMD on BGC-823 cell apoptosis. Cells were treated with PBS, DOC, DLLD or DLLD plus UTMD for $48 \mathrm{~h}$. (A) Cell apoptosis analysis by Annexin V and propidium iodide staining. (B) Quantified levels of cell apoptosis. Values are presented as the mean \pm SD ( $\mathrm{n}=5$ for each group). ${ }^{*} \mathrm{P}<0.05$ and ${ }^{* * * *} \mathrm{P}<0.001$ vs. Control. ${ }^{\# \# / *} \mathrm{P}<0.001$ vs. DOC. ${ }^{\& \& \&} \mathrm{P}<0.001$ vs. DLLD. DOC, docetaxel; DLLD, DOC-loaded lipid microbubble; UTMD, ultrasound-triggered microbubble destruction.

minimizing dose and toxicity, DLLD combined with UTMD has attracted attention in the field of solid tumor treatment (33-37). In the present study, the effect of DLLD in combination with UTMD on the growth of a cultured gastric cancer cell line, BGC-823, was investigated. The results demonstrated that combination treatment with DLLD and UTMD exhibited the maximum inhibitory effect on tumor cell growth, primarily by arresting the cell cycle in the $G_{2} / M$ phase, inhibiting cell DNA synthesis, promoting cell apoptosis and disrupting MMP, when compared with treatment with DOC or DLLD alone.

A previous study by Kang et al (35) reported that DLLD combined with UTMD could effectively inhibit the growth 

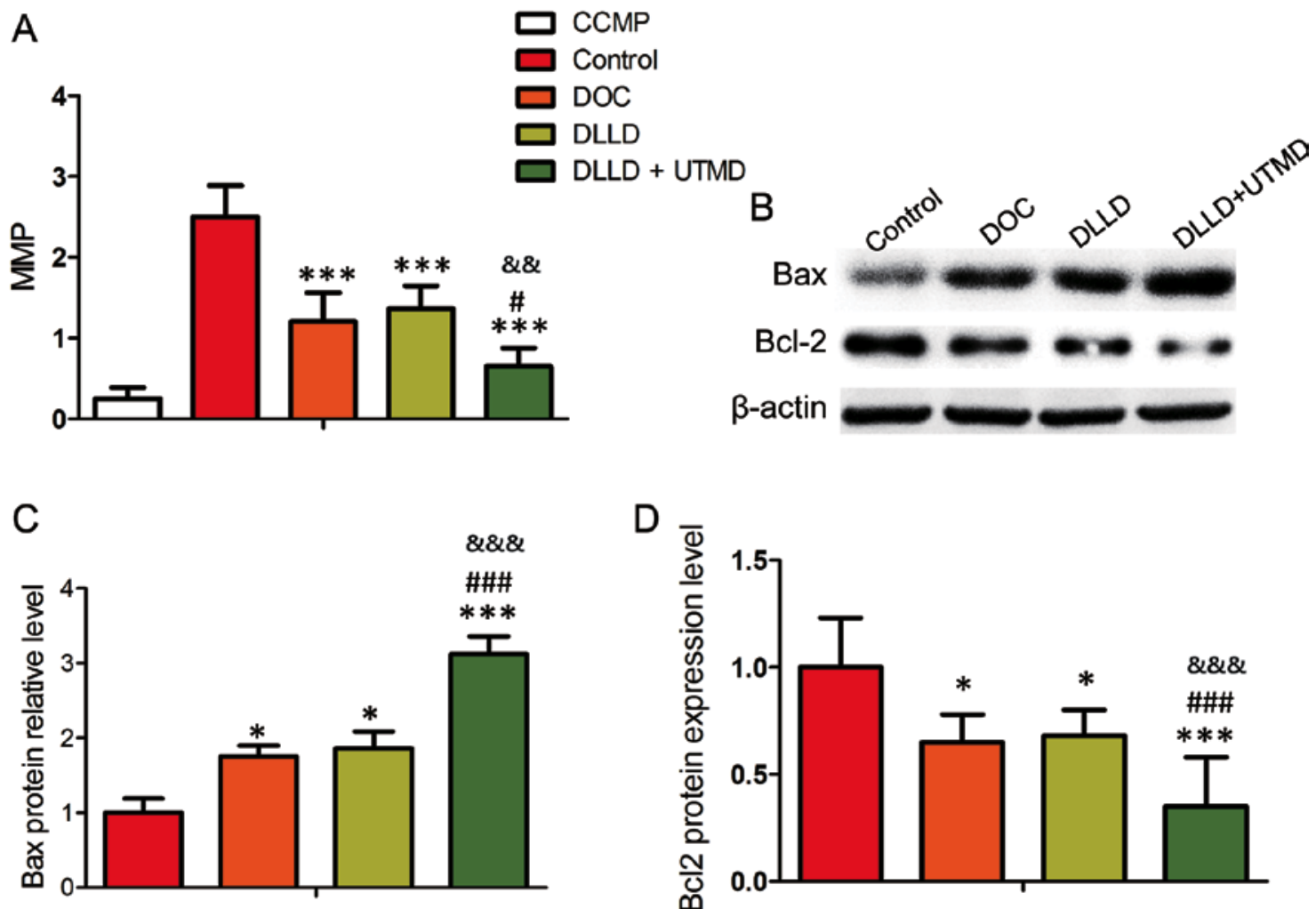

Figure 4. Effect of DLLD combined with UTMD on the MMP of BGC-823 cells. Cells were treated with PBS, DOC, DLLD or DLLD plus UTMD for $48 \mathrm{~h}$. (A) MMP assay by staining with JC-1. (B) Western blot analysis of Bcl-2 and Bax expression. Quantified protein levels of (C) Bax and (D) Bcl-2. Values are presented as the mean $\pm \mathrm{SD}\left(\mathrm{n}=5\right.$ for each group). ${ }^{*} \mathrm{P}<0.05$ and ${ }^{* * * *} \mathrm{P}<0.001$ vs. Control. ${ }^{\#} \mathrm{P}<0.05$ and ${ }^{\# \# / 1} \mathrm{P}<0.001$ vs. DOC. ${ }^{\& \&} \mathrm{P}<0.01$ and ${ }^{\& \& \&} \mathrm{P}<0.001$ vs. DLLD. DOC, docetaxel; DLLD, DOC-loaded lipid microbubble; UTMD, ultrasound-triggered microbubble destruction; MMP, mitochondrial membrane potential.

of VX2 rabbit liver tumors by deferring proliferation and promoting apoptosis. Studies investigating the effect of DLLD combined with UTMD on the growth of other tumors, such as H22 HCC or MHCC-H hepatocellular carcinoma xenografts and prostate carcinoma xenografts, have also demonstrated that DLLD combined with UTMD was the most effective strategy for the inhibition of tumor cell proliferation and the promotion of apoptosis $(28,38,39)$. Consistent with the aforementioned results, the results of the present study indicated that DLLD combined with UTMD could significantly inhibit DNA synthesis, promote cell accumulation in the $\mathrm{G}_{2} / \mathrm{M}$ phase and stimulate cell apoptosis.

The underlying molecular mechanism of DOC-induced cell cycle arrest and apoptosis may be associated with the high expression of p53, a well-characterized molecule that mediates cell cycle arrest and cell apoptosis (40). An increasing amount of evidence has suggested that $\mathrm{p} 53$ serves a critical role in sensitizing tumor cells to DOC. A previous study demonstrated that activating p53 sensitized colorectal cancer to treatment with DOC (41). Another study demonstrated that the p53 pathway was responsible for mediating tumor cell cycle arrest and cell apoptosis in response to combination treatment with DOC and resveratrol (42). In addition, a recent clinical study demonstrated that the nanocomplex carrying the p53 gene in combination with DOC could significantly block solid tumor development (43). The present study identified that DLLD combined with UTMD induced the highest expression level of p53 and its downstream effector, p21, in the BGC-823 cell line. Therefore, it was concluded that the tumor-destroying effect of DLLD combined with UTMD was at least partly mediated by promoting the expression of $\mathrm{p} 53$.

It has previously been reported that ultrasound combined with microbubbles induces cavitation, resulting in mitochondrial damage and subsequently mitochondria-dependent cell apoptosis $(44,45)$. Cavitation is associated with inducing the opening of the mitochondrial permeability transition pore (44). The present study found that DLLD combined with UTMD could significantly lower MMP levels of BGC-823 cells. Furthermore, the expression of Bcl-2 (anti-apoptotic factor) was significantly inhibited and Bax (which is pro-apoptotic factor) was significantly promoted, following combination treatment with DLLD and UTMD. Bcl-2 and Bax are mitochondrial membrane proteins, and the ratio of Bcl-2 to Bax determines whether cells undergo apoptosis (46). A previous study using DOC-loaded human serum albumin nanoparticles for the treatment of breast cancer cells observed that the nanoparticles could significantly increase the expression of Bax, thereby elevating the ratio of Bax to Bcl-2, leading to cell apoptosis (47). A different study has also demonstrated that taxotere could abrogate the pro-apoptotic function of Bcl-2 (48). Therefore, we speculate that the cavitation-induced instability of the mitochondrial membrane by UTMD may be further enhanced by DOC, resulting in strong cell apoptosis.

In conclusion, the results of the present study demonstrated that combination treatment with DLLD and UTMD could more effectively inhibit the growth of a gastric cell line, through cell 
cycle arrest, promotion of apoptosis and disruption of MMP, when compared with treatment with DOC or DLLD alone. To the best of our knowledge, this is the first study that focused on investigating the effect of combination treatment with DLLD and UTMD on the growth of a gastric cancer cell line. The findings suggested that DLLD plus UTMD could be a promising novel strategy for the treatment of gastric cancer.

\section{Acknowledgements}

Not applicable.

\section{Funding}

This project was supported by the Key Research and Development Plan from the Jiangxi Provincial Science and Technology Department (grant no. 20171BBG70062).

\section{Availability of data and materials}

The datasets used and/or analyzed during the present study are available from the corresponding author on reasonable request.

\section{Authors' contributions}

JWW conceived and designed this study. BL, PZ, HLL and LH performed all of the experiments and data analysis. BL and PZ wrote the manuscript. JWW reviewed the manuscript. All the authors read and approved the final manuscript.

\section{Ethics approval and consent to participate}

Not applicable.

\section{Patient consent for publication}

Not applicable.

\section{Competing interests}

The authors declare that they have no competing interests.

\section{References}

1. Torre LA, Siegel RL, Ward EM and Jemal A: Global cancer incidence and mortality rates and trends-an update. Cancer Epidemiol Biomarkers Prev 25: 16-27, 2016.

2. Chen W, Zheng R, Baade PD, Zhang S, Zeng H, Bray F, Jemal A, Yu XQ and He J: Cancer statistics in China, 2015. CA Cancer J Clin 66: 115-132, 2016.

3. Dadashzadeh K, Peppelenbosch MP and Adamu AI: Helicobacter pylori pathogenicity factors related to gastric cancer. Can J Gastroenterol Hepatol 2017: 7942489, 2017.

4. Buckland G, Travier N, Huerta JM, Bueno-de-Mesquita HB, Siersema PD, Skeie G, Weiderpass E, Engeset D, Ericson U, Ohlsson B, et al: Healthy lifestyle index and risk of gastric adenocarcinoma in the EPIC cohort study. Int J Cancer 137: 598-606, 2015.

5. Laszewicz W, Iwanczak F, Iwanczak B and Task Force of the Polish Society of Gastroenterology; Task Force of the Polish Society of Gastroenterology: Seroprevalence of Helicobacter pylori infection in Polish children and adults depending on socioeconomic status and living conditions. Adv Med Sci 59: 147-150, 2014.

6. Ko KP, Shin A, Cho S, Park SK and Yoo KY: Environmental contributions to gastrointestinal and liver cancer in the Asia-Pacific region. J Gastroenterol Hepatol 33: 111-120, 2018.
7. Zylberberg HM, Sultan K and Rubin S: Hereditary diffuse gastric cancer: One family's story. World J Clin Cases 6: 1-5, 2018.

8. Yamashita S, Kishino T, Takahashi T, Shimazu T, Charvat H, Kakugawa Y, Nakajima T, Lee YC, Iida N, Maeda M, et al: Genetic and epigenetic alterations in normal tissues have differential impacts on cancer risk among tissues. Proc Natl Acad Sci USA 115: 1328-1333, 2018.

9. Chen B, Wang J, Gu X, Zhang J and Feng X: The DNMT3B $-579 \mathrm{G}>\mathrm{T}$ polymorphism is significantly associated with the risk of gastric cancer but not lung cancer in chinese population. Technol Cancer Res Treat 16: 1259-1265, 2017.

10. Ajani JA: Evolving chemotherapy for advanced gastric cancer. Oncologist 3 (Suppl 10): S49-S58, 2005.

11. Menges $M$ and Hoehler T: Current strategies in systemic treatment of gastric cancer and cancer of the gastroesophageal junction. J Cancer Res Clin Oncol 135: 29-38, 2009.

12. Tripathi PP, Arami H, Banga I, Gupta J and Gandhi S: Cell penetrating peptides in preclinical and clinical cancer diagnosis and therapy. Oncotarget 9: 37252-37267, 2018.

13. Mullick Chowdhury S, Lee T and Willmann JK: Ultrasound-guided drug delivery in cancer. Ultrasonography 36 : 171-184, 2017.

14. Li P, Zheng Y, Ran H, Tan J, Lin Y, Zhang Q, Ren J and Wang Z: Ultrasound triggered drug release from 10-hydroxycamptothecin-loaded phospholipid microbubbles for targeted tumor therapy in mice. J Control Release 162: 349-354, 2012.

15. Negishi Y, Endo-Takahashi Y and Maruyama K: Gene delivery systems by the combination of lipid bubbles and ultrasound. Drug Discov Ther 10: 248-255, 2016.

16. Elnaggar MA, Subbiah R, Han DK and Joung YK: Lipid-based carriers for controlled delivery of nitric oxide. Expert Opin Drug Deliv 14: 1341-1353, 2017.

17. Delalande A, Kotopoulis S, Postema M, Midoux P and Pichon C: Sonoporation: Mechanistic insights and ongoing challenges for gene transfer. Gene 525: 191-199, 2013.

18. Hynynen K, McDannold N, Sheikov NA, Jolesz FA and Vykhodtseva N: Local and reversible blood-brain barrier disruption by noninvasive focused ultrasound at frequencies suitable for trans-skull sonications. Neuroimage 24: 12-20, 2005.

19. Mayer CR, Geis NA, Katus HA and Bekeredjian R: Ultrasound targeted microbubble destruction for drug and gene delivery. Expert Opin Drug Deliv 5: 1121-1138, 2008.

20. Chen WS, Matula TJ and Crum LA: The disappearance of ultrasound contrast bubbles: Observations of bubble dissolution and cavitation nucleation. Ultrasound Med Biol 28: 793-803, 2002.

21. Wu W, Cheng Y, Guo BH and Wu Q: Pharmacokinetics of liver-targeted docetaxel liposomes modified with 6-O-acyl-D-galactose esters in rabbits. Biomed Rep 2: 545-548, 2014.

22. Deng CX, Sieling F, Pan H and Cui J: Ultrasound-induced cell membrane porosity. Ultrasound Med Biol 30: 519-526, 2004.

23. Zhou Y, Kumon RE, Cui J and Deng CX: The size of sonoporation pores on the cell membrane. Ultrasound Med Biol 35: 1756-1760, 2009.

24. Mehier-Humbert S, Bettinger T, Yan F and Guy RH: Plasma membrane poration induced by ultrasound exposure: Implication for drug delivery. J Control Release 104: 213-222, 2005.

25. Uemura N, Kikuchi S, Sato Y, Ohnuma H, Okamoto K, Miyamoto H, Hirakawa M, Sagawa T, Fujikawa K, Takahashi Y, et al: A phase II study of modified docetaxel, cisplatin, and S-1 (mDCS) chemotherapy for unresectable advanced gastric cancer. Cancer Chemother Pharmacol 80: 707-713, 2017.

26. Mitsui Y, Sato Y, Miyamoto H, Fujino Y, Takaoka T, Miyoshi J, Kagawa M, Ohnuma H, Hirakawa M, Kubo T, et al: Trastuzumab in combination with docetaxel/cisplatin/S-1 (DCS) for patients with HER2-positive metastatic gastric cancer: Feasibility and preliminary efficacy. Cancer Chemother Pharmacol 76: 375-382, 2015.

27. Kim HS, Ryu MH, Zang DY, Ryoo BY, Yang DH, Cho JW, Lim MS, Kim MJ, Han B, Choi DR, et al: Phase II study of docetaxel, oxaliplatin, and S-1 therapy in patients with metastatic gastric cancer. Gastric Cancer 19: 579-585, 2016.

28. Zhang Y, Chang R, Li M, Zhao K, Zheng $\mathrm{H}$ and Zhou X: Docetaxel-loaded lipid microbubbles combined with ultrasound-triggered microbubble destruction for targeted tumor therapy in MHCC-H cells. Onco Targets Ther 9: 4763-4771, 2016.

29. Chazotte B: Labeling mitochondria with JC-1. Cold Spring Harb Protoc 2011: pii: pdb.prot065490, 2011. 
30. Tangutur AD, Kumar D, Krishna KV and Kantevari S: Microtubule targeting agents as cancer chemotherapeutics: An overview of molecular hybrids as stabilizing and destabilizing agents. Curr Top Med Chem 17: 2523-2537, 2017.

31. Farha NG and Kasi A: Docetaxel. In: StatPearls [Internet]. StatPearls Publishing, Treasure Island, FL, 2019.

32. Lyseng-Williamson KA and Fenton C: Docetaxel: A review of its use in metastatic breast cancer. Drugs 65: 2513-2531, 2005.

33. Haag P, Frauscher F, Gradl J, Seitz A, Schäfer G, Lindner JR, Klibanov AL, Bartsch $G$, Klocker $H$ and Eder IE: Microbubble-enhanced ultrasound to deliver an antisense oligodeoxynucleotide targeting the human androgen receptor into prostate tumours. J Steroid Biochem Mol Biol 102: 103-113, 2006.

34. Xing W, Gang WZ, Yong Z, Yi ZY, Shan XC and Tao RH: Treatment of xenografted ovarian carcinoma using paclitaxel-loaded ultrasound microbubbles. Acad Radiol 15: $1574-1579,2008$.

35. Kang J, Wu X, Wang Z, Ran $\mathrm{H}, \mathrm{Xu} \mathrm{C}$, Wu J, Wang $\mathrm{Z}$ and Zhang Y: Antitumor effect of docetaxel-loaded lipid microbubbles combined with ultrasound-targeted microbubble activation on VX2 rabbit liver tumors. J Ultrasound Med 29 61-70, 2010

36. Grainger SJ, Serna JV, Sunny S, Zhou Y, Deng CX and El-Sayed ME: Pulsed ultrasound enhances nanoparticle penetration into breast cancer spheroids. Mol Pharm 7: 2006-2019, 2010.

37. Shi F, Yang F, He X, Zhang Y, Wu S, Li M, Zhang Y, Di W, Dou $\mathrm{J}$ and $\mathrm{Gu} \mathrm{N}$ : Inhibitory effect of epirubicin-loaded lipid microbubbles with conjugated anti-ABCG2 antibody combined with therapeutic ultrasound on multiple myeloma cancer stem cells. J Drug Target 24: 34-46, 2016.

38. Ren ST, Shen S, He XY, Liao YR, Sun PF, Wang B, Zhao WB, Han SP, Wang YL and Tian T: The effect of docetaxel-loaded micro-bubbles combined with low-frequency ultrasound in H22 hepatocellular carcinoma-bearing mice. Ultrasound Med Biol 42: 549-560, 2016.
39. Yang Y, Bai W, Chen Y, Nan S, Lin Y, Ying T and Hu B: Low-frequency ultrasound-mediated microvessel disruption combined with docetaxel to treat prostate carcinoma xenografts in nude mice: A novel type of chemoembolization. Oncol Lett 12: 1011-1018, 2016.

40. Kim JH, Yoon EK, Chung HJ, Park SY, Hong KM, Lee $\mathrm{CH}$, Lee YS, Choi K, Yang Y, Kim K and Kim IH: p53 acetylation enhances Taxol-induced apoptosis in human cancer cells. Apoptosis 18: 110-120, 2013.

41. Guo J, Yang Y, Linghu E, Zhan Q, Brock MV, Herman JG, Zhang B and Guo M: RASSF10 suppresses colorectal cancer growth by activating P53 signaling and sensitizes colorectal cancer cell to docetaxel. Oncotarget 6: 4202-4213, 2015.

42. Singh SK, Banerjee S, Acosta EP, Lillard JW and Singh R: Resveratrol induces cell cycle arrest and apoptosis with docetaxel in prostate cancer cells via a p53/ p21WAF1/CIP1 and p27KIP1 pathway. Oncotarget 8: 17216-17228, 2017.

43. Pirollo KF, Nemunaitis J, Leung PK, Nunan R, Adams J and Chang EH: Safety and efficacy in advanced solid tumors of a targeted nanocomplex carrying the p53 gene used in combination with docetaxel: A phase 1B study. Mol Ther 24: 1697-1706, 2016.

44. Zhao L, Feng Y, Shi A, Zong Y and Wan M: Apoptosis induced by microbubble-assisted acoustic cavitation in K562 cells: The predominant role of the cyclosporin a-dependent mitochondrial permeability transition pore. Ultrasound Med Biol 41: 2755-2764, 2015.

45. Yang SL, Tang KQ, Bai WK, Zhao YW, Shen E, Tao JJ and $\mathrm{Hu}$ B: Combined low-frequency ultrasound and microbubble contrast agent for the treatment of benign prostatic hyperplasia. J Endourol 27: 1020-1026, 2013.

46. Maes ME, Schlamp CL and Nickells RW: BAX to basics: How the BCL2 gene family controls the death of retinal ganglion cells. Prog Retin Eye Res 57: 1-25, 2017.

47. Kordezangeneh M, Irani S, Mirfakhraie R, Esfandyari-Manesh M, Atyabi F and Dinarvand R: Regulation of BAX/BCL2 gene expression in breast cancer cells by docetaxel-loaded human serum albumin nanoparticles. Med Oncol 32: 208, 2015.

48. Haldar S, Basu A and Croce CM: Bcl2 is the guardian of microtubule integrity. Cancer Res 57: 229-233, 1997. 